\title{
Hedyotis diffusa Willd suppresses metastasis in 5-fluorouracil-resistant colorectal cancer cells by regulating the TGF- $\beta$ signaling pathway
}

\author{
ZIJUN LAI ${ }^{1,2}$, ZHAOKUN YAN ${ }^{1,2}$, WUJIN CHEN $^{3}$, JUN PENG $^{1,2}$, JIANYU FENG $^{1,2}$, \\ QIONGYU LI ${ }^{1,2}$, YIYI JIN ${ }^{1,2}$ and JIUMAO LIN ${ }^{1,2}$ \\ ${ }^{1}$ Academy of Integrative Medicine, Biomedical Research Center; ${ }^{2}$ Fujian Key Laboratory of Integrative Medicine on Geriatrics, \\ Fujian University of Traditional Chinese Medicine, Fuzhou, Fujian 350122; ${ }^{3}$ Oncology Department of \\ The Affiliated People's Hospital of Fujian University of Traditional Chinese Medicine, Fuzhou, Fujian 350004, P.R. China
}

Received December 19, 2016; Accepted July 18, 2017

DOI: $10.3892 / \mathrm{mmr} .2017 .7500$

\begin{abstract}
Colorectal cancer (CRC) is one of the most common malignant tumors of the digestive tract, and threatens the survival and health of patients with CRC. Chemotherapy remains one of the main therapeutic approaches for patients with CRC; however, drug resistance limits the long-term use. CRC cells with multi-drug resistance (MDR) exhibit increased survival times and metastatic potential, which may lead to the recurrence and metastasis of CRC. In addition, MDR is one of the major causes of chemotherapy failure in clinical treatment. Hedyotis diffusa Willd (HDW) has been used in the treatment of inflammation-associated diseases and malignant tumors, including CRC. The authors previously demonstrated that HDW could reverse MDR in CRC cells; however, its underlying mechanism, particularly in MDR-associated metastasis, remains to be elucidated. In the present study, the drug-resistant CRC cell line HCT-8/5-fluorouracil (5-FU) was used to investigate the effect of HDW on the growth and metastasis of cancer cells. Cell viability was assessed using the MTT assay. Cell adhesion potential was evaluated using adhesion experiments. Cell migration was assessed using wound healing and Transwell assays. The mRNA and protein expression levels of crucial factors in the transforming growth factor- $\beta$ (TGF- $\beta$ ) signaling pathway, including TGF- $\beta$, Mothers against decapentaplegic homolog 4 (SMAD4), neural (N)-cadherin,
\end{abstract}

Correspondence to: Professor Jiumao Lin, Academy of Integrative Medicine, Biomedical Research Center, Fujian University of Traditional Chinese Medicine, 1 Qiuyang Road, Minhou Shangjie, Fuzhou, Fujian 350122, P.R. China

E-mail: jiumaolin@hotmail.com

Abbreviations: CRC, colorectal cancer; EEHDW, ethanol extract of Hedyotis diffusa Willd; TGF- $\beta$, transforming growth factor- $\beta$; EMT, epithelial-mesenchymal transition

Key words: Hedyotis diffusa Willd, colorectal cancer, metastasis, epithelial-mesenchymal transition, TGF- $\beta$ pathway and epithelial (E)-cadherin, were analyzed using the reverse transcription-semi-quantitative polymerase chain reaction and western blotting, respectively. The results demonstrated that the HCT-8/5-FU cell line was more resistant to 5-FU and thus can be used as the resistant cell model. HDW was able to inhibit the viability, and adhesive, migratory and invasion potential of the HCT-8/5-FU cells. In addition, HDW was able to downregulate the expression of TGF- $\beta$, SMAD 4 and N-cadherin, and upregulate E-cadherin, at the gene and protein level. In conclusion, the results demonstrated that HDW may suppress the metastasis of 5-FU-resistant CRC cells via regulation of the TGF- $\beta$ signaling pathway, which was also considered to be one of the underlying mechanisms of its anti-CRC effect.

\section{Introduction}

Colorectal cancer (CRC) is one of the most prevalent malignant tumors of the digestive tract and $>1.2$ million individuals have been diagnosed with CRC, with 600,000 mortalities reported annually, which severely impairs human survival and health worldwide (1). Although surgical resection remains the primary treatment option for CRC, chemotherapy has become an optimal and unique approach for patients with advanced-stage CRC who are not surgical candidates, particularly patients with metastases and those who require adjuvant treatment to prevent relapse (2-5). As a frequently used chemotherapeutic drug for CRC (6), 5-fluorouracil (5-FU) can yield multidrug resistance (MDR) during chemotherapy, which is the primary cause of chemotherapy failure, and the recurrence and metastasis of CRC $(7,8)$.

Following acquisition of MDR, the migratory and adhesive potential of tumor cells is enhanced, which is the leading cause of metastasis, recurrence and invasion in malignant tumors $(5,9)$. Epithelial-mesenchymal transition (EMT) is one of the fundamental modes of metastasis, and is defined as the biological process through which epithelial cells differentiate into mesenchymal cells under the stimulation of specific factors $(10,11)$.

Transforming growth factor- $\beta$ (TGF- $\beta$ ) is a vital factor that is responsible for regulating the EMT process (12). TGF- $\beta$ 
serves a dual role in inhibiting and promoting the incidence and progression of malignant tumors. During the onset of malignant tumors, TGF- $\beta$ is capable of inhibiting cancer progression by suppressing cancer cell proliferation, accelerating cancer cell apoptosis and preventing the incidence of oncogenic inflammation. In advanced stages, TGF- $\beta$ is overexpressed, and instead can accelerate the progression and metastasis of malignant tumors, by promoting cell metastasis, immune evasion and angiogenesis through the regulation of EMT (13-17). With respect to the TGF- $\beta$ signaling pathway as a target, inhibiting the TGF- $\beta$ pathway within tumor cells can decrease the incidence of EMT, thereby reducing the production of mesenchymal-like cells and decreasing the incidence of tumor metastasis (17-19).

Hedyotis diffusa Willd (HDW) belongs to the Rubiaceae family, and is a traditional Chinese herbal medicine that can dissipate heat and toxicity, alleviate abscesses and masses, promote blood flow, and ease pain (20). It has been applied in the treatment of various inflammation-associated diseases and malignant tumors, and is proven to possess anticancer effects against CRC and other malignant tumors, without evident adverse events $(21,22)$. The authors previously demonstrated that HDW can inhibit proliferation and angiogenesis, induce apoptosis, and reverse MDR in CRC cells (23-27). However, the underlying mechanism, particularly in MDR-associated metastasis, remains to be elucidated.

To further study the anti-CRC effects and underlying molecular mechanism of HDW, particularly in terms of MDR-associated metastasis, the present study used the 5-FU resistant CRC cell line HCT-8/5-FU as a high-metastasis model (9) to analyze the effect of HDW on the viability, and migratory and invasive potential of HCT-8/5-FU cells, and on the regulation of the TGF- $\beta$ signaling pathway.

\section{Materials and methods}

Materials and reagents. RPMI-1640 medium (cat. no. C11875500BT), fetal bovine serum (FBS; cat. no. 10099-141), penicillin-streptomycin (cat. no. SV30010), 0.25\% trypsin-EDTA (cat. no. 25200-072), Pierce radioimmunoprecipitation assay buffer (cat. no. 89901), Pierce BCA Protein Assay kit (cat. no. 23227) and SuperSignal ${ }^{\mathrm{TM}}$ West Pico Chemiluminescent Substrate (cat. no. 34080) were all purchased from Thermo Fisher Scientific, Inc. (Waltham, MA, USA). MTT was obtained from Sigma-Aldrich (Merck KGaA, Darmstadt, Germany). The BD BioCoat Matrigel Invasion Chamber was purchased from BD Biosciences (San Jose, CA, USA). The PrimeScript RT Reagent kit was provided by Takara Biotechnology Co., Ltd. (Dalian, China). TRIzol reagent was obtained from Thermo Fisher Scientific, Inc. Anti-neural (N)-cadherin (cat. no. ab98952) and epithelial (E)-cadherin (cat. no. ab128804) antibodies were purchased from Abcam (Cambridge, UK). Anti-TGF- $\beta$ (cat. no. 3711), Mothers against decapentaplegic homolog 4 (SMAD4; cat. no. 3716) and $\beta$-actin (cat. no. 4967) antibodies were provided by Cell Signaling Technology, Inc. (Danvers, MA, USA). Horseradish peroxidase (HRP)-conjugated goat anti-rabbit secondary antibody (cat. no. E030120) was purchased from EarthOx Life Science (Millbrae, CA, USA).

Preparation of ethanol extract of HDW (EEHDW). EEHDW was prepared as described previously (25). Stock solutions of
EEHDW were prepared by dissolving the EEHDW powder in $100 \%$ dimethyl sulfoxide (DMSO) to a final concentration of $500 \mathrm{mg} / \mathrm{ml}$ and stored at $-20^{\circ} \mathrm{C}$. The working concentrations of EEHDW were made by diluting the stock solution in the culture medium. The final concentrations of DMSO in the medium were $<0.5 \%$.

Cell culture. The human colorectal 5-FU resistant cell line HCT-8/5-FU and its parental cell line HCT-8 were obtained from Nanjing KeyGen Biotech Co., Ltd. (Nanjing, China). Cells were maintained in RPMI-1640 medium containing $10 \%$ (v/v) FBS, $100 \mathrm{U} / \mathrm{ml}$ penicillin and $100 \mathrm{~g} / \mathrm{ml}$ streptomycin, while the $\mathrm{HCT} / 5-\mathrm{FU}$ cells were cultured with an additional $15 \mathrm{~g} / \mathrm{ml} 5-\mathrm{FU}$, at $37^{\circ} \mathrm{C}$ in a humidified atmosphere containing $5 \% \mathrm{CO}_{2}$.

Cell viability evaluation. Cell viability was assessed by MTT assay. HCT-8, HCT-8/5-FU or HCT-8 cells were seeded into 96 -well plates at a density of $1 \times 10^{4}$ cells/well in $0.1 \mathrm{ml}$ media and were treated with various concentrations of 5-FU $(0,25,50,100,200,400,800$ and $1600 \mathrm{mM})$ for $48 \mathrm{~h}$. HCT-8/5-FU cells were seeded into 96 -well plates at a density of $8 \times 10^{3}$ cells/well in $0.1 \mathrm{ml}$ medium. Cells were treated with various concentrations $(0,0.5,1$ and $2 \mathrm{mg} / \mathrm{ml})$ of EEHDW for different periods of time. A total of $100 \mathrm{ml}$ MTT $(0.5 \mathrm{mg} / \mathrm{ml}$ in PBS) was added to each well and the samples were incubated for an additional $4 \mathrm{~h}$ at $37^{\circ} \mathrm{C}$. The purple-blue MTT formazan precipitate was dissolved in $100 \mu \mathrm{l}$ DMSO. The absorbance was measured at $570 \mathrm{~nm}$ using an ELISA reader (ELX800; BioTek Instruments, Inc., Winooski, VT, USA). The resistance index (RI) of the HCT-8/5-FU cells to 5-FU was calculated by dividing the drug concentration required to inhibit growth by $50 \%\left(\mathrm{IC}_{50}\right)$ for HCT-8/5-FU cells by the $\mathrm{IC}_{50}$ value for the parental cells (HCT-8). $\mathrm{IC}_{50}$ values were determined using nonlinear regression analysis.

Wound healing assay. HCT-8/5-FU cells were seeded into 6 -well plates at a density of $5 \times 10^{5}$ cells/well in $2 \mathrm{ml}$ medium. After $24 \mathrm{~h}$ of incubation, cells were scratched vertically in each well using a P200 pipette tip. A phase-contrast inverted microscope at a magnification of x100 was used to observe three randomly-selected fields of view along the scraped line and images of each well were captured. Cells were then treated with indicated concentrations $(0,0.5,1$ and $2 \mathrm{mg} / \mathrm{ml})$ of EEHDW for $24 \mathrm{~h}$, and another set of images were captured by the same method. A reduction in the width of the scratch indicates a sign of migration.

Measurement of cell migration and invasion by Transwell assay. The migration assay assay was performed using Transwell cell culture chambers, and the invasion assay was performed using Transwell cell culture chambers coated with Matrigel (BD Biosciences). The inserts were placed within a 24-well chamber containing $0.7 \mathrm{ml}$ RPMI-1640 with $10 \%$ FBS as a chemoattractant. A total of $2.5 \times 10^{5}$ cells were seeded into 6 -well plates per well and were treated with different concentrations $(0,0.5,1$ and $2 \mathrm{mg} / \mathrm{ml})$ of EEHDW for $24 \mathrm{~h}$. Cells $\left(5 \times 10^{4}\right.$ cells) were seeded into the inserts suspended in $0.2 \mathrm{ml}$ serum-free RPMI-1640 medium. Cells were incubated at $37^{\circ} \mathrm{C}$ with $5 \% \mathrm{CO}_{2}$ for 12 or $24 \mathrm{~h}$ for the migration and invasion 
assays, respectively. The upper surface of the filter was scraped to remove non-migratory cells. Migratory and invasive cells were fixed with ice-cold $4 \%$ paraformaldehyde for $10 \mathrm{~min}$ and stained with crystal violet at room temperature for $15 \mathrm{~min}$. For quantification, the average number of migratory or invasive cells/field was assessed by counting five random fields under a phase-contrast microscope (FMIL/DFC295; Leica Microsystems $\mathrm{GmbH}$, Wetzlar, Germany) at a magnification of $\mathrm{x} 200$.

Adhesion assay. HCT-8/5-FU cells were seeded into 6-well plates at a density of $2 \times 10^{5}$ cells/well in $2 \mathrm{ml}$ medium and were treated with different concentrations $(0,0.5,1$ and $2 \mathrm{mg} / \mathrm{ml})$ of EEHDW for $24 \mathrm{~h}$. Cells were digested and suspended in RPMI-1640 medium. Cells were seeded in 6-well plates at a density of $2 \times 10^{4}$ cells/well and incubated for $2 \mathrm{~h}$. The supernatant was discarded, and the cells were washed two times with PBS. Adhered cells were stained with $0.1 \%$ crystal violet at room temperature for $15 \mathrm{~min}$. The adhered cells were counted under a phase-contrast microscope at a magnification of $\mathrm{x} 200$

RNA extraction and reverse transcription-semi-quantitative polymerase chain reaction ( $R T$-sqPCR) analysis. HCT-8/5-FU cells were seeded into 6 -well plates in $2 \mathrm{ml}$ medium and were treated with indicated concentrations of EEHDW for $24 \mathrm{~h}$. Total RNA was isolated with TRIzol reagent. Oligo (dT)-primed RNA $(1 \mu \mathrm{g})$ was reverse-transcribed using the PrimeScript RT Reagent kit (Takara Biotechnology Co., Ltd.), according to the manufacturer's protocol. The cDNA was used to determine the mRNA levels of TGF- $\beta$, SMAD4, E-cadherin and N-cadherin using sqPCR with PCR kit (Master mix; Applied Biosystems, Thermo Fisher Scientific, Inc.). GAPDH was used as an internal control. The RT-sqPCR conditions were performed for 30 cycles as follows: Denaturation at $94^{\circ} \mathrm{C}$ for $40 \mathrm{sec}$, annealing at $60^{\circ} \mathrm{C}$ for $40 \mathrm{sec}$ and extension at $72^{\circ} \mathrm{C}$ for $45 \mathrm{sec}$. The following primers were used for the amplification of transcripts: TGF- $\beta$ forward, 5'-ACCCACAACGAAATCTATGACA-3' and reverse, 5'-CTAAGGCGAAAGCCCTCAAT-3'; SMAD4 forward, 5'-GATTTGCGTCAGTGTCATCG-3' and reverse, 5'-AGTCTAAAGGTTGTGGGTCTG-3'; E-cadherin forward, 5'-CTACAATGCCGCATCGCTT-3' and reverse, 5'-GTATAC GTAGGGAAACTCTCTCGG TC-3'; N-cadherin forward, 5'-AAGAACGCCAGGCCAAACAAC-3' and reverse, 5'-CTG GCTCAAGTCATAGTCCTG GTCT-3'; and GAPDH forward, 5'-GTCATCCATGACAACTTTGG-3' and reverse, 5'-GAG CTTGACAAAGTGGTCGT-3'. The PCR was repeated in 3 independent times. A Thermal Cycler (Bio-Rad S1000; Hercules, CA, USA) was used to perform the experiment. Samples were analyzed by $1.5 \%$ agarose gel electrophoresis and the DNA bands were examined using a gel documentation system (Gel Doc XR+; Bio-Rad Laboratories, Inc., Hercules, CA, USA).

Western blot analysis. HCT-8/5-FU cells were seeded into $25 \mathrm{~cm}^{2}$ flasks at a density of $2.5 \times 10^{5}$ cells $/ \mathrm{ml}$ in $5 \mathrm{ml}$ medium. Cells were treated with the indicated concentrations of EEHDW for $24 \mathrm{~h}$. The treated cells were lyzed with radioimmunoprecipitation assay buffer containing protease and phosphatase inhibitor cocktails. Total protein concentrations were determined by BCA assay. Equal amounts of total protein $(50 \mu \mathrm{g})$ were resolved via SDS-PAGE on a $10 \%$ gel and electroblotted onto polyvinylidene difluoride membranes. The membranes were blocked with $5 \%$ nonfat dry milk at room temperature for $2 \mathrm{~h}$, and probed with primary antibodies TGF- $\beta(1: 1,000$ dilution), SMAD4 (1:1,000 dilution), E-cadherin (1:1,000 dilution), $\mathrm{N}$-cadherin (1:1,000 dilution), and $\beta$-actin $(1: 1,000$ dilution) overnight at $4^{\circ} \mathrm{C}$. Membranes were subsequently incubated with the HRP-conjugated secondary antibody (1:2,000 dilution) at room temperature for $1 \mathrm{~h}$ and followed by enhanced chemiluminescence detection using SuperSignal West Pico Chemiluminescent Substrate. Image Lab ${ }^{\text {TM }}$ software (version 3.0; Bio-Rad Laboratories, Inc.) was used for densitometric analysis and quantification of western blots.

Statistical analysis. All data are presented as the mean of three repeats and were analyzed using the SPSS package for Windows (version 22.0; IBM Corp., Armonk, NY, USA). Statistical analysis of the data was performed using the Student's t-test and one-way analysis of variance, followed by Dunnett's and the Least Significant Difference post hoc tests, as appropriate. Differences with $\mathrm{P}<0.05$ was considered to indicate a statistically significant difference.

\section{Results}

HCT-8/5-FU cells are resistant to treatment with 5-FU. To verify the 5-FU resistance profiles of the CRC cell lines, MTT assays were used to detect the cell viability and the resistance index (RI) was used to evaluate the degree of resistance. HCT-8 and HCT-8/5-FU cells were exposed to different concentrations of 5-FU for $48 \mathrm{~h}$. As shown in Fig. 1, the results demonstrated that the viability of the HCT- 8 cells was significantly decreased following treatment with $\geq 25 \mu \mathrm{M}$ 5-FU compared with the untreated cells, whereas the viability of the HCT-8/5-FU cells was significantly decreased following treatment with $\geq 800 \mu \mathrm{M} 5$-FU. The half-maximal inhibitory concentration of 5-FU was $119.48 \mathrm{mM}$ in HCT-8 cells and $2.803 \mathrm{mM}$ in HCT-8/5-FU cells, and the RI for 5 -FU was 23.45 (>1.5) (data not shown). These results indicated that the HCT-8/5-FU cells used in the present study can be used as a 5-FU resistance model.

EEHDW inhibits the viability of HCT-8/5-FU cells. The effect of EEHDW on the viability of HCT-8/5-FU cells was determined by MTT assay. As demonstrated in Fig. 2, the cell viability was decreased in response to different concentrations $(0.5,1.0$ and $2.0 \mathrm{mg} / \mathrm{ml})$ of EEHDW for 12, 24 and $48 \mathrm{~h}$. The results demonstrated that treatment with EEHDW resulted in a time- and dose-dependent inhibitory effect in HCT-8/5-FU cells.

EEHDW inhibits the migration and invasion of HCT-8/5-FU cells. The effect of EEHDW on the migration of HCT-8/5-FU cells was determined using a wound healing assay. As demonstrated in Fig. 3, $24 \mathrm{~h}$ following the introduction of a wound, the untreated HCT-8/5-FU cells migrated into the clear area, whereas treatment with EEHDW inhibited the migration of HCT-8/5-FU cells in a dose-dependent manner. In order to investigate further, Transwell assays were performed to determine the effects of EEHDW on the migration and invasion of 


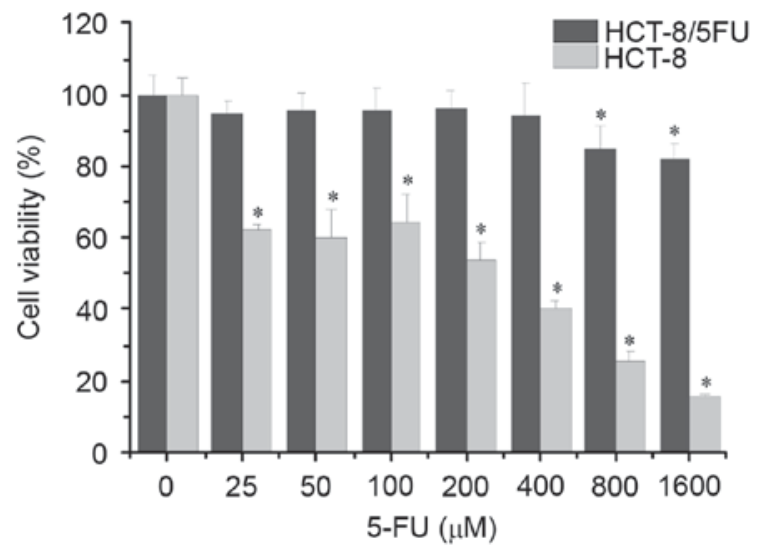

Figure 1. 5-FU resistance profiles in HCT-8/5-FU and HCT-8 cells. Cells were treated with various concentrations of 5 -FU for $48 \mathrm{~h}$ and the cell viability was determined using an MTT assay. Data were normalized to the viability of untreated control cells and shown as the mean \pm standard deviation from three independent experiments. ${ }^{*} \mathrm{P}<0.05$ vs. the control cells. $5-\mathrm{FU}$, 5 -fluorouracil.

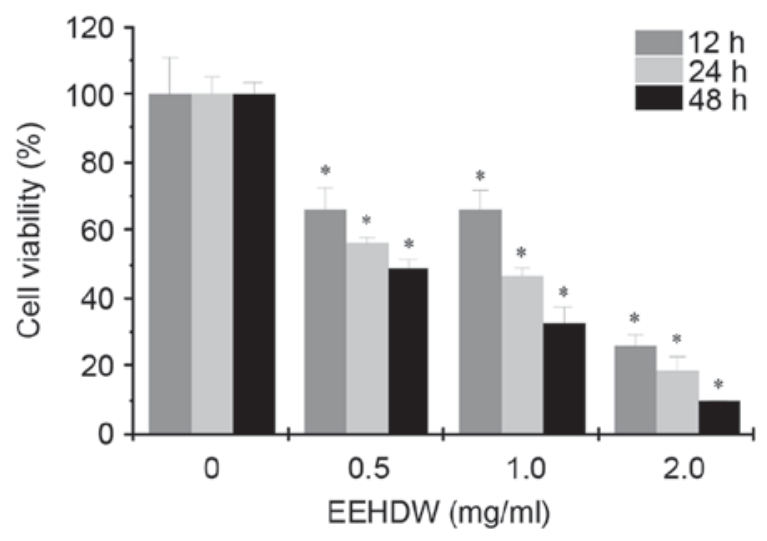

Figure 2. Effect of EEHDW on the viability of HCT-8/5-FU cells. Cells were treated with various concentrations of EEHDW for 12, 24 and $48 \mathrm{~h}$, and cell viability was determined using an MTT assay. Data were normalized to the viability of the untreated control cells and shown as the mean \pm standard deviation from three independent experiments. ${ }^{*} \mathrm{P}<0.05$ vs. the control cells. EEHDW, ethanol extract of Hedyotis diffusa Willd.

HCT-8/5-FU cells. As demonstrated in Fig. 4, following treatment with different concentrations of EEHDW, the number of migratory and invasive cells decreased in a dose-dependent manner. These results suggested that EEHDW can inhibit metastasis in HCT-8/5-FU cells.

EEHDW inhibits adhesion in HCT-8/5-FU cells. The effect of EEHDW on adhesion in HCT-8/5-FU cells was determined using the adhesion assay. As demonstrated in Fig. 5, following treatment with different concentration of EEHDW, compared with the control, the adhesive ability of the HCT-8/5-FU cells was attenuated.

EEHDW regulates the TGF- $\beta$ pathway in $H C T-8 / 5-F U$ cells. To further study the mechanism of EEHDW's antimetastatic effect, the mRNA and protein expression of TGF- $\beta$ pathway-associated factors in HCT-8/5-FU cells was determined using RT-sqPCR and western blotting, respectively. As demonstrated in Fig. 6, treatment with EEHDW downregulated the expression of mRNA and protein levels of TGF- $\beta$, SMAD4 and $\mathrm{N}$-cadherin, and upregulated the mRNA and protein levels of E-cadherin, in a dose-dependent manner, suggesting that EEHDW may inhibit the metastasis of HCT-8/5-FU cells through the suppression of the TGF- $\beta$ signaling pathway.

\section{Discussion}

The MDR of tumor cells refers to the phenomenon through which tumor cells demonstrate resistance to multiple drugs with varying mechanisms and chemical structures. The incidence of tumor cell MDR is a leading cause of chemotherapy failure in clinical treatment. Following the acquisition of drug resistance, the metastasis of tumor cells is enhanced, which is the primary factor leading to tumor recurrence, invasion and metastasis (10). Therefore, it is necessary to identify novel drugs that can reverse MDR and inhibit the metastasis of tumor cells. HDW is a traditional Chinese medicine and exhibits anticancer effects. The authors previously demonstrated that HDW can reverse MDR in CRC (28). The results of the present study demonstrated that HCT-8/5-FU cells exhibit drug resistance to 5-FU. The EEHDW was able to inhibit cell proliferation, and suppress the migratory, invasive and adhesive potential of HCT-8/5-FU cells, suggesting that EEHDW exerts an in vitro effect by inhibiting the metastasis of CRC cells with MDR.

Previous investigations have demonstrated that metastatic tumor cells undergo EMT, which includes the loss of cell-cell adhesion, destruction of the tumor basement membrane and extracellular matrix, and reconstruction of the cytoskeleton, enhancing cell mobility and inducing metastasis $(29,30)$. As a part of reversible cell reorganization, EMT is regulated by multiple circuits at the transcriptional, post-transcriptional, and translational levels $(31,32)$. Following EMT, tumor cells may invade, and also secrete an array of growth factors and chemokines, which can stimulate and recruit stromal cells, thereby indirectly accelerating tumor cell migration and permeating into the circulation system to form metastatic lesions (15). Through these processes, epithelioid malignant cells acquire migratory and invasive activity.

Human TGF- $\beta$ is a $25-\mathrm{kDa}$ disulfide-linked dimeric protein. EMT mediated by TGF- $\beta$ is proven to serve a pivotal role in the infiltration and metastasis of malignant tumors (33). Consequently, TGF- $\beta$ is necessary to evaluate the effect of TGF- $\beta$-mediated EMT upon the infiltration and metastasis of tumors, which provides strategies for reducing the metastatic rate of malignant tumors. Targeting the TGF- $\beta$ signaling pathway can decrease the incidence of EMT, thereby decreasing the production of mesenchymal-like cells and lowering the incidence of tumor metastasis $(34,35)$. As a transcription factor, SMAD4 serves a crucial role in the transduction of the TGF- $\beta$ signal (36). Epithelial and mesenchymal cells display distinct phenotypes and functions. Epithelial cells exhibit basal polarity and express high levels of epithelium-labeled E-cadherin to form intimate epithelial cell adhesion (37). E-cadherin is considered to be a main regulator of EMT, and the downregulated expression of E-cadherin is a rate-limiting step in EMT. In the presence of downregulated expression of E-cadherin, non-invasive tumors can be transformed into highly-invasive tumors (38). Mesenchymal cells lack cell polarity and highly express mesenchyme-labeled N-cadherin (39). Alterations in 

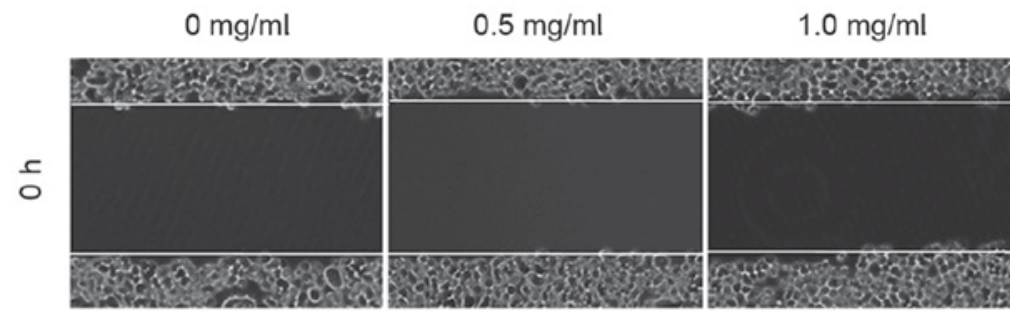

$2.0 \mathrm{mg} / \mathrm{ml}$
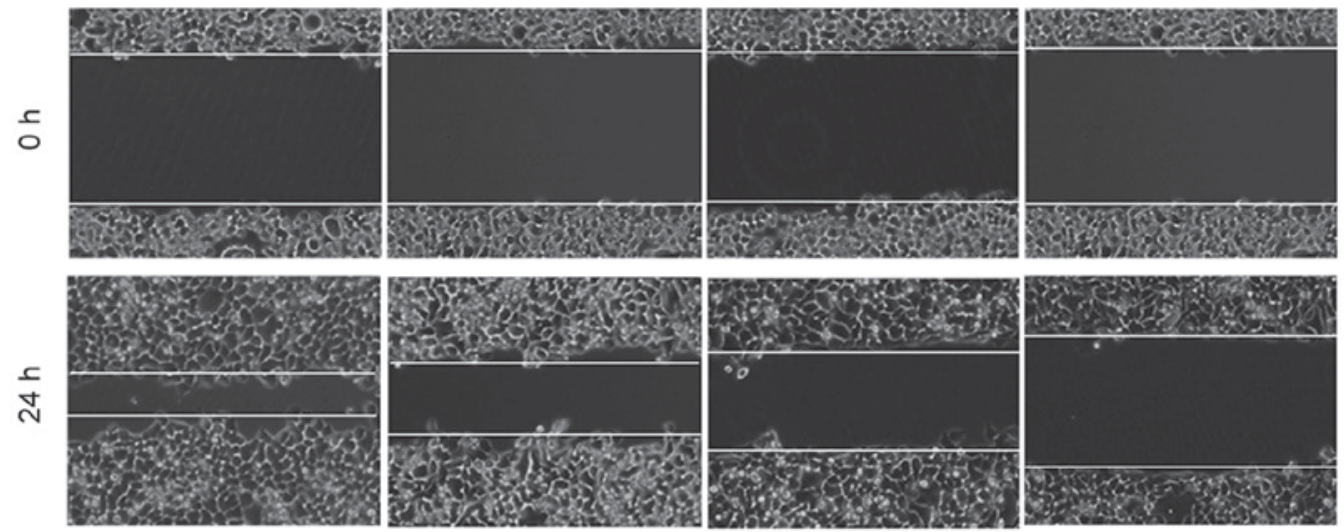

Figure 3. Effect of EEHDW on wound healing in HCT-8/5-FU cells. HCT-8/5-FU cells were treated with the indicated concentrations of EEHDW for $24 \mathrm{~h}$. The wound healing patterns of HCT-8/5-FU cells were observed using phase-contrast microscopy. Images were captured at a magnification of x100. Images are representative of three independent experiments. EEHDW, ethanol extract of Hedyotis diffusa Willd.
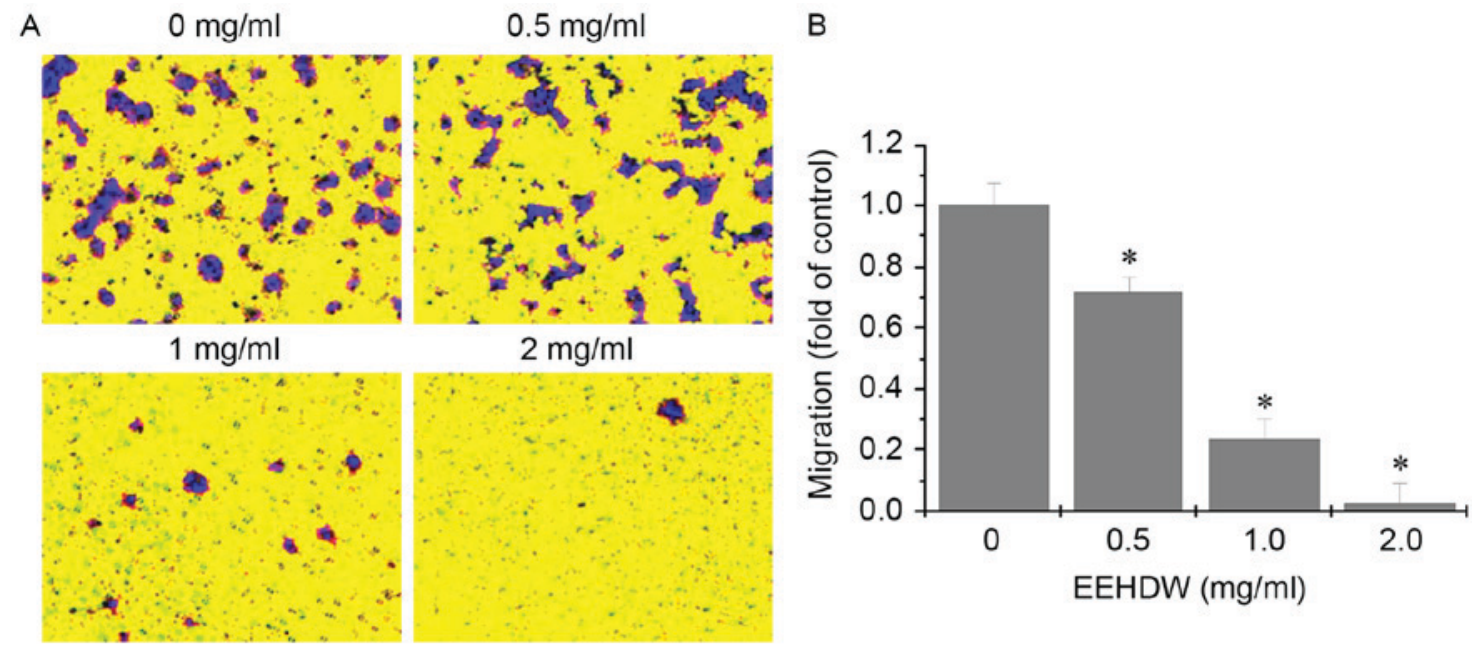

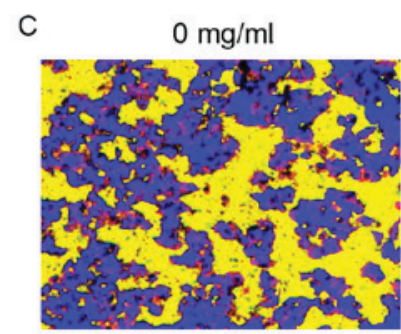

$1 \mathrm{mg} / \mathrm{ml}$

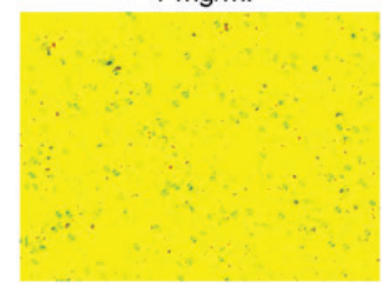

$0.5 \mathrm{mg} / \mathrm{ml}$

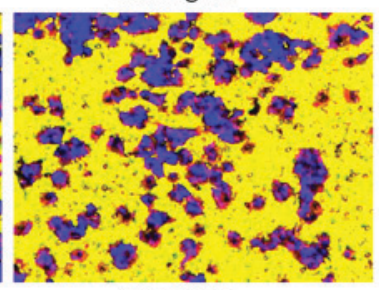

$2 \mathrm{mg} / \mathrm{ml}$

D

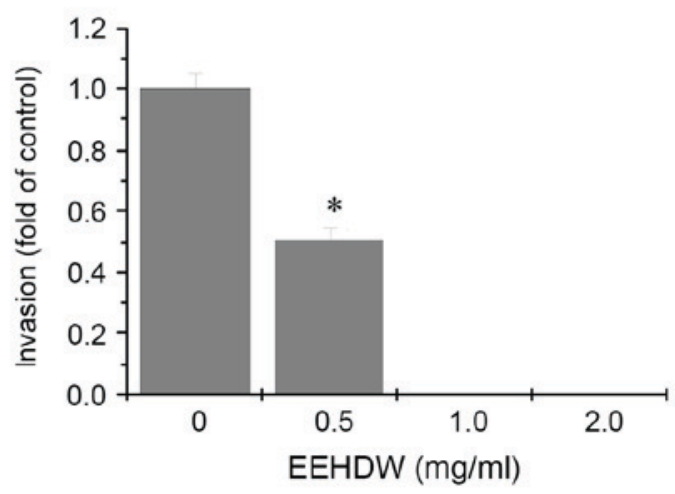

Figure 4. Effect of EEHDW on migration and invasion in HCT-8/5-FU cells. HCT-8/5-FU cells were treated with the indicated concentrations of EEHDW for $24 \mathrm{~h}$. (A) Migration of HCT-8/5-FU cells was determined using Transwell cell culture chambers. (B) The average number of migratory cells was counted in five randomly-selected fields. (C) Invasion of HCT-8/5-FU cells was determined using Transwell cell culture chambers with membranes coated with Matrigel matrix. (D) The average number of invasive cells was counted in five randomly-selected fields. The data were normalized to the levels of migration and invasion in the control cells $(100 \%)$. Magnification, $\mathrm{x} 200$. Data are presented as the mean \pm standard deviation of three independent experiments. ${ }^{*} \mathrm{P}<0.05 \mathrm{vs}$. the control cells. EEHDW, ethanol extract of Hedyotis diffusa Willd.

the expression levels of E-cadherin and N-cadherin are a key mechanism underlying the EMT of tumor cells, and are regulated by the TGF- $\beta$ signaling transduction pathway. The results of the present study demonstrated that EEHDW can downregulate the 

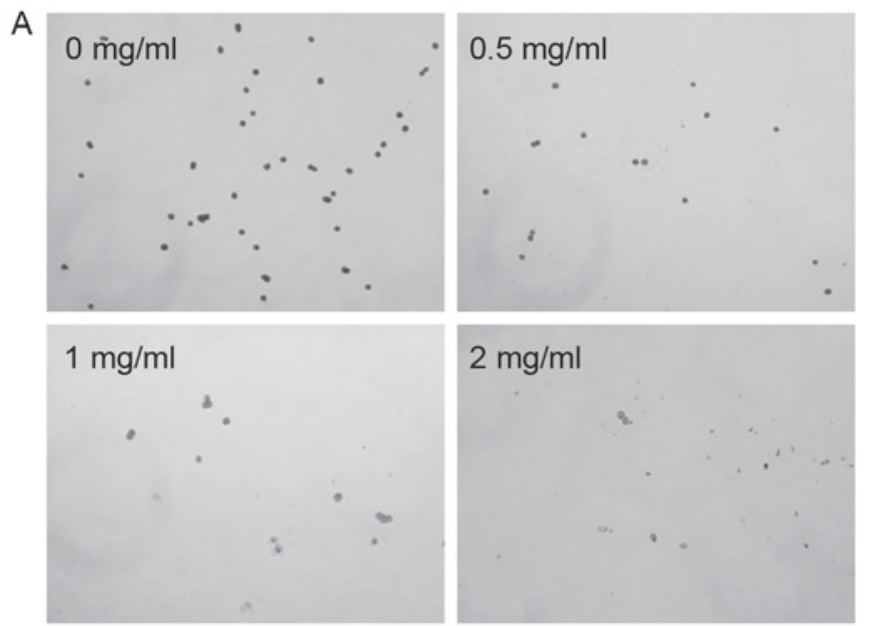

B

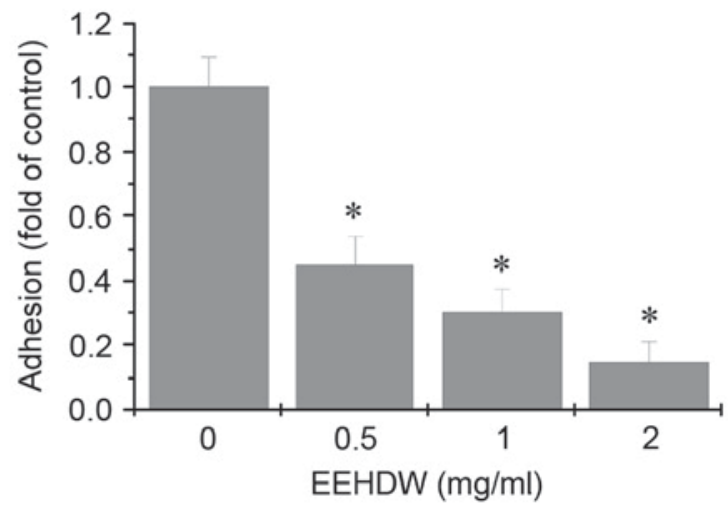

Figure 5. Effect of EEHDW on the adhesion of HCT-8/5-FU cells. HCT-8/5-FU cells were treated with the indicated concentrations of EEHDW for $24 \mathrm{~h}$. (A) The adhesion pattern of HCT-8/5-FU cells was observed using phase-contrast microscopy. Images were captured at a magnification of x200. Images are representative of three independent experiments. (B) The average number of adhesive cells was counted in five randomly-selected fields. Data were normalized to the adhesion of control cells and shown as the mean \pm standard deviation from three independent experiments. "P<0.05 vs. the control cells. EEHDW, ethanol extract of Hedyotis diffusa Willd.

A

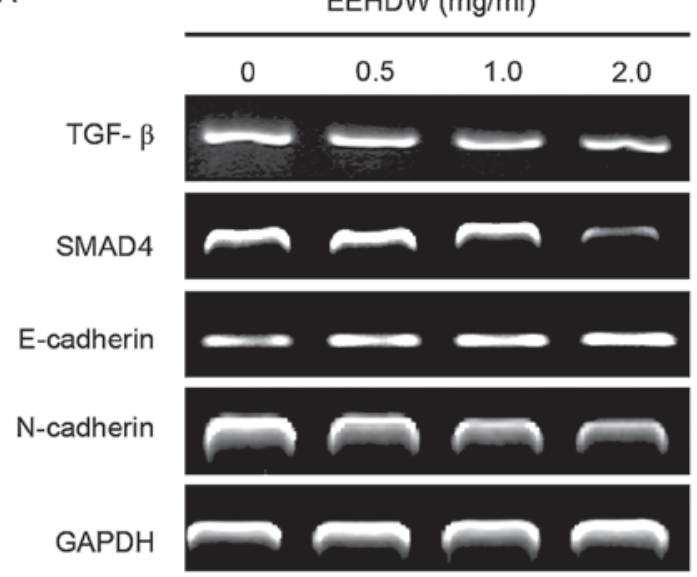

C

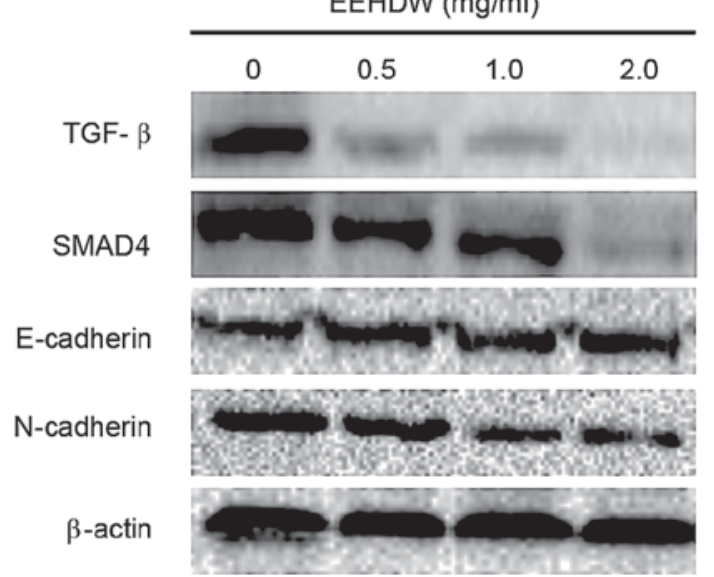

B

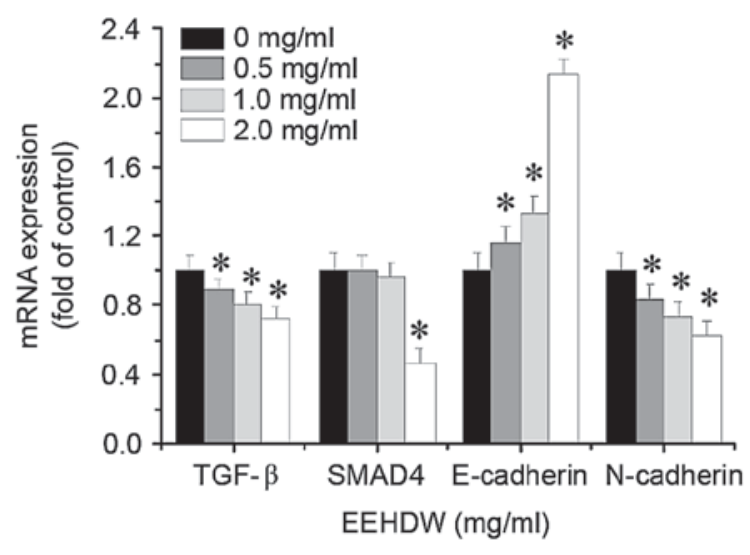

D

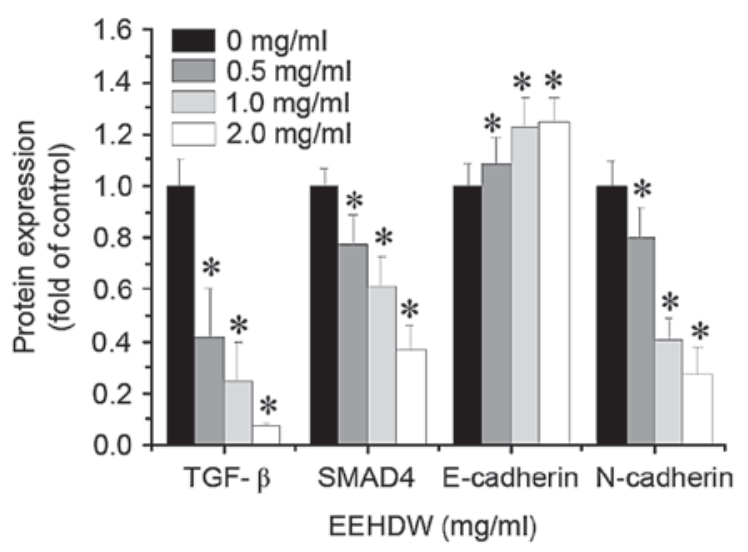

Figure 6. Effect of EEHDW on the activation of the TGF- $\beta$ signaling pathway in HCT-8/5-FU cells. HCT-8/5-FU cells were treated with the indicated concentrations of EEHDW for $24 \mathrm{~h}$. (A) The mRNA expression levels of TGF- $\beta$, SMAD4, E-cadherin and N-cadherin in HCT-8/5-FU cells were determined and (B) quantified by RT-sqPCR analysis. (C) The protein expression levels of TGF- $\beta$, SMAD4, E-cadherin and N-cadherin in HCT- $8 / 5$-FU cells were determined and (D) quantified by western blotting. $\beta$-actin or GAPDH was used as the internal control for western blotting or RT-sqPCR, respectively. Images are representatives of three independent experiments. Data were normalized to the expression of untreated controls (100\%) and shown as the mean \pm standard deviation from three independent experiments. ${ }^{*} \mathrm{P}<0.05$ vs. the control cells. EEHDW, ethanol extract of Hedyotis diffusa Willd; TGF- $\beta$, transforming growth factor- $\beta$; SMAD4, Mothers against decapentaplegic homolog 4; E, epithelial; N, neural; RT-sqPCR, reverse transcriptionsemi-quantitative polymerase chain reaction. 
expression of TGF- $\beta$, SMAD4 and N-cadherin, and upregulate the expression of E-cadherin, in HCT-8/5-FU cells. Therefore, EEHDW can inhibit the incidence of EMT by suppressing the activation of the TGF- $\beta$ signaling pathway, thereby inhibiting the metastasis of CRC cells.

In conclusion, EEHDW exerts its antimetastatic activity through suppression of TGF- $\beta$ /SMAD4 signaling pathway-mediated EMT. The results of the present study may provide a foundation for the development of a multi-potent anticancer agent for the clinical treatment of CRC.

\section{Acknowledgements}

The present study was sponsored by the Research Fund for the Doctoral Program of Higher Education of China (grant no. 20133519110003), Project Funding for the Training of Young and Middle-aged Backbone Personnel of Fujian Provincial Health and Family Planning Commission (grant no. 2016-ZQN-67), and the Developmental Fund of Chen Keji Integrative Medicine (grant nos. CKJ2014013 and CKJ2015007).

\section{References}

1. Siegel RL, Miller KD and Jemal A: Cancer statistics, 2016. CA Cancer J Clin 66: 7-30, 2016.

2. Cunningham D, Atkin W, Lenz HJ, Lynch HT, Minsky B, Nordlinger B and Starling N: Colorectal cancer. Lancet 375: 1030-1047, 2010.

3. Jiang WQ, Fu FF, Li YX, Wang WB, Wang HH, Jiang HP and Teng LS: Molecular biomarkers of colorectal cancer: Prognostic and predictive tools for clinical practice. J Zhejiang Univ Sci B 13: 663-675, 2012.

4. Aakif M, Balfe P, Elfaedy O, Awan FN, Pretorius F, Silvio L, Castinera $\mathrm{C}$ and Mustafa $\mathrm{H}$ : Study on colorectal cancer presentation, treatment and follow-up. Int J Colorectal Dis 31: 1361-1363, 2016.

5. Du B and Shim JS: Targeting Epithelial-Mesenchymal Transition (EMT) to Overcome Drug Resistance in Cancer. Molecules 21: pii: E965, 2016.

6. Phillips TA, Howell A, Grieve RJ and Welling PG: Pharmacokinetics of oral and intravenous fluorouracil in humans. J Pharm Sci 69: 1428-1431, 1980.

7. Juchum M, Günther M and Laufer SA: Fighting cancer drug resistance: Opportunities and challenges for mutation-specific EGFR inhibitors. Drug Resist Update 20: 12-28, 2015.

8. Kim JK, Kang KA, Piao MJ, Ryu YS, Han X, Fernando PM, Oh MC, Park JE, Shilnikova K, Boo SJ, et al: Endoplasmic reticulum stress induces 5 -fluorouracil resistance in human colon cancer cells. Environ Toxicol Pharmacol 44: 128-133, 2016.

9. Shen A, Chen H, Chen Y, Lin J, Lin W, Liu L, Sferra TJ and Peng J: Pien Tze Huang overcomes multidrug resistance and epithelial-mesenchymal transition in human colorectal carcinoma cells via suppression of TGF- $\beta$ pathway. Evid Based Complement Alternat Med 2014: 679436, 2014.

10. Pecina-Slaus N, Cicvara-Pecina T and Kafka A: Epithelial-tomesenchymal transition: Possible role in meningiomas. Front Biosci (Elite Ed) 4: 889-896, 2012.

11. Guarino M, Rubino B and Ballabio G: The role of epithelialmesenchymal transition in cancer pathology. Pathology 39: 305-318, 2007.

12. Roberts AB: Molecular and cell biology of TGF-beta. Miner Electrolyte Metab 24: 111-119, 1998.

13. Derynck R, Akhurst RJ and Balmain A: TGF-beta signaling in tumor suppression and cancer progression. Nat Genet 29: $117-129,2001$.
14. Trapani JA: The dual adverse effects of TGF-beta secretion on tumor progression. Cancer Cell 8: 349-350, 2005.

15. Heldin $\mathrm{CH}$, Vanlandewijck $\mathrm{M}$ and Moustakas A: Regulation of EMT by TGF $\beta$ in cancer. FEBS Lett 586: 1959-1970, 2012.

16. Massagué J: TGFbeta in cancer. Cell 134: 215-230, 2008.

17. Thiery JP, Acloque H, Huang RY and Nieto MA: Epithelialmesenchymal transitions in development and disease. Cell 139: 871-890, 2009.

18. Brunen D, Willems SM, Kellner U, Midgley R, Simon I and Bernards R: TGF- $\beta$ : An emerging player in drug resistance. Cell Cycle 12: 2960-2968, 2013.

19. Moustakas A and Heldin P: TGF $\beta$ and matrix-regulated epithelial to mesenchymal transition. Biochim Biophys Acta 1840: 2621-2634, 2014.

20. Song LR: Zhonghuabencao. Shanghai Science and Technology Press, Shanghai, p433, 1999.

21. Yang JJ, Hsu HY, Ho YH and Lin CC: Comparative study on the immunocompetent activity of three different kinds of Peh-Hue-Juwa-Chi-Cao, Hedyotis diffusa, H. corymbosa and Mollugo pentaphylla after sublethal whole body x-irradiation. Phytother Res 11: 428-432, 1997.

22. Li R, Zhao HR and Lin YM: Anti-tumor effect and protective effect on chemotherapeutic damage of water soluble extracts from Hedyotis diffusa. J Chin Pharmaceu Sci 11: 54-58, 2002.

23. Cai Q, Lin J, Wei L, Zhang L, Wang L, Zhan Y, Zeng J, Xu W, Shen A, Hong Z and Peng J: Hedyotis diffusa Willd inhibits colorectal cancer growth in vivo via inhibition of STAT3 signaling pathway. Int J Mol Sci 13: 6117-6128, 2012.

24. Lin J, Wei L, Shen A, Cai Q, Xu W, Li H, Zhan Y, Hong Z and Peng J: Hedyotis diffusa Willd extract suppresses Sonic hedgehog signaling leading to the inhibition of colorectal cancer angiogenesis. Int J Oncol 42: 651-656, 2013.

25. Lin J, Chen Y, Wei L, Chen X, Xu W, Hong Z, Sferra TJ and Peng J: Hedyotis diffusa Willd extract induces apoptosis via activation of the mitochondrion-dependent pathway in human colon carcinoma cells. Int J Oncol 37: 1331-1338, 2010.

26. Lin J, Wei L, Xu W, Hong Z, Liu X and Peng J: Effect of Hedyotis diffusa Willd extract on tumor angiogenesis. Mol Med Rep 4: 1283-1288, 2011.

27. Lin M, Lin J, Wei L, Xu W, Hong Z, Cai Q, Peng J and Zhu D: Hedyotis diffusa Willd extract inhibits HT-29 cell proliferation via cell cycle arrest. Exp Ther Med 4: 307-310, 2012.

28. Li Q, Wang X, Shen A, Zhang Y, Chen Y, Sferra T, Lin J and Peng J: Hedyotis diffusa Willd overcomes 5-fluorouracil resistance in human colorectal cancer HCT-8/5-FU cells by downregulating the expression of P-glycoprotein and ATP-binding casette subfamily G member 2. Exp Ther Med 10: 1845-1850, 2015.

29. Valastyan S and Weinberg RA: Tumor metastasis: Molecular insights and evolving paradigms. Cell 147: 275-292, 2011.

30. Moustakas A and Heldin $\mathrm{CH}$ : The regulation of TGFbeta signal transduction. Development 136: 3699-3714, 2009.

31. Nieto MA: Epithelial plasticity: A common theme in embryonic and cancer cells. Science 342: 1234850, 2013.

32. Kalluri R and Weinberg RA: The basics of epithelial-mesenchymal transition. J Clin Invest 119: 1420-1428, 2009.

33. Shi Y and Massagué J: Mechanisms of TGF-beta signaling from cell membrane to the nucleus. Cell 113: 685-700, 2003.

34. Zi Z, Chapnick DA and Liu X: Dynamics of TGF- $\beta /$ SMAD signaling. FEBS Lett 586: 1921-1928, 2012.

35. Massagué J: How cells read TGF-beta signals. Nat Rev Mol Cell Biol 1: 169-178, 2000.

36. Massagué $\mathrm{J}$ and Wotton D: Transcriptional control by the TGF-beta/Smad signaling system. EMBO J 19: 1745-1754, 2000

37. Batlle E, Sancho E, Francí C, Domínguez D, Monfar M, Baulida J and García De Herreros A: The transcription factor Snail is a repressor of E-cadherin gene expression in epithelial tumour cells. Nat Cell Biol 2: 84-89, 2000.

38. Lamouille S, Xu J and Derynck R: Molecular mechanisms of epithelial-mesenchymal transition. Nat Rev Mol Cell Biol 15: 178-196, 2014.

39. Tanaka T, Goto $\mathrm{K}$ and Iino M: Sec8 modulates TGF- $\beta$ induced EMT by controlling $\mathrm{N}$-cadherin via regulation of Smad3/4. Cell Signal 29: 115-126, 2017. 